\title{
Río de Janeiro y otros modernismos
}

\author{
Rio de Janeiro and other Modernisms \\ Rio de Janeiro e outros modernismos
}

\section{Beatriz Resende}

UNIVERSIDADE FEDERAL DO RIO DE JANEIRO, BRASIL

Profesora titular de la Facultad de Letras en la Universidade Federal

do Rio de Janeiro (UFRJ). Doctora en Literatura Comparada

de la misma institución. Autora, entre otras publicaciones, de

Contemporâneos, expressões da literatura brasileira no século XXI

(Casa da Palavra; Biblioteca Nacional, 2008) Apontamentos de crítica

cultural (Aeroplano, 2000) y Lima Barreto e o Rio de faneiro em

fragmentos (UFRJ; Universidade Estadual de Campinas [Unicamp],

1993). Editora de Cocaína, literatura e outros companheiros de

viagem (Casa da Palavra, 2006), Rio literário (Casa da Palavra,

2005) y Toda crônica (reunião das crônicas de Lima Barreto)

(Agir, 2004).Correo electrónico: resende.beatriz@gmail.com

\footnotetext{
Artículo de reflexión

Traducción de Maria Cândida Ferreira de Almeida y Mauricio Arévalo Arbeláez (magíster en Literatura de la Universidad de los Andes, correo electrónico: marevalo53@hotmail.com). Documento accesible en línea desde la siguiente dirección: http://revistas.javeriana.edu.co

doi:10.11144/Javeriana.CL18-35.rjom
} 


\section{Resumen}

A partir de una reflexión sobre la modernidad y sus implicaciones, este artículo se propone una lectura de la arquitectura estética y social propia de la ciudad de Río de Janeiro. También se revisará una literatura art-decó que frecuentemente está fuera del canon modernista pero que sustentó un diálogo con el movimiento modernista.

Palabras clave: modernismo, arquitectura, literatura art-decó. Palabras descriptor:

Modernismo (Arquitectura), estética arquitectónica, arte deco, literatura, Rio de Janeiro (Brasil)

\section{Abstract}

From a reflection on modernity and its implications, this paper proposes a reading one's own aesthetic and social architecture of the city of Rio de Janeiro. Also a literature review art-deco which is often outside the modernist canon but that sustained dialogue with the modernist movement.

Keywords: modernism, architecture, literature art-deco. Keywords plus: Modernism (architecture), architectureaesthetics, art deco, literature, Rio de Janeiro (Brazil)

RECIBIDO: 4 DE MARZO DE 2013. EVALUADO: 27 DE ABRIL DE 2013. ACEPTADO: 27 DE ABRIL DE 2013.

\section{Cómo citar este artículo:}

Resende, Beatriz. "Río de Janeiro y otros modernismos".

Cuadernos de Literatura 18.35 (2014): 73-85.

\section{(c) (1) $\Theta(9)$}


EL MODERNIS MO HA sido, seguramente, el movimiento más fuerte y más grande de la literatura brasileña. Fue tan importante, transformador y duradero que terminó pagando el precio de volverse canónico. Cien años después de la Semana de Arte Moderno, no tiene sentido hablar del movimiento modernista en Brasil sin una propuesta de revisión de valores, de cuestionamiento de dogmas y, sobre todo, sin asumir una actitud saludable de convivencia con la pluralidad.

La modernidad que surge con los manifiestos, actitudes, propuestas y manifestaciones culturales y artísticas de la vanguardia, desde el primer modernismo hasta el modernismo alto, ya calmado, domado o acomodado en ciertos casos, estuvo siempre fuertemente atada a las modificaciones expresivas de la vida en las ciudades. Además, todos los procesos de modernización estuvieron acompañados por intervenciones, más o menos necesarias, en la geografía, el aspecto y la organización humana de la ciudad. Raymond Williams afirma en su importante ensayo de 1986, "Percepciones metropolitanas y la emergencia del modernismo": Está hoy claro que existen conexiones decisivas entre prácticas e ideas de los movimientos de vanguardia del siglo XX y las condiciones y relaciones específicas de las metrópolis del siglo XX. Esta evidencia estuvo allí todo el tiempo y, en muchos casos, es obvia. Sin embargo, hasta hace poco, ha sido difícil separar esta relación histórica y cultural específica del aún más específico y ampliamente celebrado (y condenado) sentido de lo moderno. (45)

El ya largo camino que vengo recorriendo en la tentativa de relectura de las manifestaciones del modernismo en Río de Janeiro se ha dado en la perspectiva de asociar la vida cultural y artística a las modificaciones ocurridas en la ciudad. Para ello se ha examinado el modernismo carioca a partir de las observaciones de su especificidad, incluso la de haber sido capital federal, a través de una mirada que presupone, sobre todo, la pluralidad capaz de percibir varios modernismos desarrollados bajo la hegemonía (o a pesar de ella) del concepto de moderno.

Esta mirada que pretende caracterizar un modernismo plural, reconociendo a los diversos "compañeros de viaje", parte de las siguientes actitudes:

1. La identificación de múltiples movimientos simultáneos, que coexisten en el tiempo y el espacio, dejan marcas diferenciadas en la ciudad y dan a la producción cultural una perspectiva plural, antes híbrida que una y estable, como muchas veces fueron presentados los tiempos modernos. En relación con Río de Janeiro, cabe destacar la resistencia que la ciudad demostró, siempre que fue posible, al pensamiento único, y que guardó la mayoría de veces una tendencia a la oposición crítica. 
2. El cuestionamiento de la canonización oficial, que terminó no solo absorbiendo la rebeldía moderna, sino también entronizando el modernismo como forma exclusiva de producir arte, al identificar lo moderno con la "alta" cultura en oposición a cualquier expresión de la "baja" cultura, comprometida con la satisfacción del público, el consumo y el gusto de capas urbanas diversas, que atenuaba las diferencias entre centro y periferia.

3. La constatación de que hubo, en la antigua capital federal, un tránsito diferente del que se dio en varias otras ciudades hacia la cultura europea, menos "devorada", como preconizaban los principios de la antropofagia, y más relacionado con el diálogo. Por otro lado, no obstante que el modelo de ciudad que la reforma de Pereira Passos deseó para la capital era el francés, realizado en la avenida Central, con esta ciudad "oficial" de elegancia francesa coexistían otras. Todavía era la ciudad portuguesa, la ciudad de los negros de la Tía Ciata, y al hablarse de Río de Janeiro, y la muchas veces olvidada, pero importante para el universo de la cultura, ciudad de los italianos. Esta era la ciudad de la diversión, con los teatros de revista y el cinematógrafo. Después sería también la ciudad del gusto americano de la Cinelandia y del skyscrapers (rascacielos).

4. Una revisión más atenta de la historia del modernismo en Río muestra que varias fronteras establecidas fueron, como son siempre las fronteras, creadas a posteriori y, en varios casos, estuvieron más orientadas a la organización del canon que al estudio de las fuentes originales. Así, en la literatura, entre los modernistas del primer momento y los últimos simbolistas, algunos más ligados al gusto popular del momento anterior, otros más conservadores, la ruptura no fue radical como se quiso instituir. También la rivalidad cultivada entre el modernismo en Río y la vanguardia paulista se hizo más folclórica de lo que parecen evidenciar la observación de varias alianzas, la asistencia a espacios como el salón de exposición del Palace Hotel, en Río, el intercambio de cartas y las contribuciones en periódicos y revistas.

5. Finalmente, la constatación de que cualquier manifestación cultural y artística que se desarrolla en Río dialoga, así no lo quiera el productor, con las calles, con el espacio público. Si el modernismo paulista fue generado y creció en los salones aristocráticos de hacendados e industriales que se iban estableciendo en el escenario económico, en Río los debates se desarrollaron de la misma manera en los cafés, las librerías del centro de la ciudad, las onces de Cinelandia, las redacciones de periódicos e, inevitablemente, en los gabinetes de reparticiones públicas. 
No quiero minimizar la importancia fundamental del movimiento modernista, responsable de innovaciones formales decisivas y de la introducción de nuevos temas, tanto cotidianos como prosaicos, que liberaron definitivamente a la literatura brasileña de un modelo de escritura conservador, aún vigente a principios del siglo XX. Fue, también, principalmente en los primeros años (los "años heroicos" del 22 al 28), la oportunidad de repensar cuestiones de identidad cultural, lo que aportó a la construcción de una idea de Brasil moderno. Lo que quiero recordar es que de este modo el movimiento se hizo hegemónico, lo que minimizó o eliminó del mapa cultural del Brasil otras manifestaciones literarias y artísticas que, ya habiendo roto con la estética parnasiana, fueron previas al movimiento modernista, además de otras, de gustos y formatos diferentes que coexistieron con las producciones que fueron incorporadas al canon modernista. $\mathrm{El}$ arquitecto Paolo Portoghesi muestra que este no fue un privilegio del modernismo brasileño cuando afirma:

La historia de la arquitectura y del gusto moderno fue escrita y reescrita con métodos y criterios diversos, mas siempre sobre la óptica del movimiento moderno, del interior de una tendencia que se rehusó desdeñosamente a reconocer la función de sus compañeros de camino. (7)

La revisión crítica que aquí proponemos se da a través de observaciones de tres etapas del modernismo en Río de Janeiro. La primera apunta a algunos de los primeros momentos de su inicio al que Márcio Doctors, hablando de las artes plásticas, designó como desvío hacia lo moderno. Estas expresiones serán ejemplos de lo que vengo llamando literatura art-déco, y permiten constatar que este estilo fue el más importante de los compañeros de viaje. Se trata de expresiones de literatura, novelas, cuentos y crónicas, mas también del arte gráfico de las revistas ilustradas. Tal "desvío" ya es evidente a inicios de los años veinte.

La segunda etapa es la del auge del gusto art-déco en Río de Janeiro, de la convivencia entre la influencia déco venida de Europa, especialmente del París de los frenéticos años veinte, y el inicio de la seducción de Hollywood. Es una fase -y esto es lo que queremos mostrar- en la que el proceso de construcción de la modernidad se da por la convivencia entre representantes del último simbolismo y los nuevos modernistas, especialmente los poetas, que crean arte y cultura. El año de 1931, por un conjunto de circunstancias, marcará el inicio de esta etapa que se extiende hasta 1935 .

Finalmente, identificaré el momento en que el modernismo empieza a enterrar la pluralidad -1935- hasta llegar a la época en que algunas de sus propuestas empiezan a correr riesgo, esto es, entre los años 1935 y 1945. Se resalta que en 1942 
se da la primera evaluación crítica importante del movimiento modernista con la célebre conferencia de Mário de Andrade en Río de Janeiro.

Como ya se dijo y no es exageración, la fuerza adquirida por la literatura modernista excluye de los estudios literarios cualquier producción que, aun siendo contemporánea o próxima a ella, no sea considerada expresión legítima del modernismo. De la misma forma, el gusto casi militante por lo indiscutiblemente nuevo, el ejercicio de formas artísticas incomprensibles o inaccesibles al gran público, se identifica con el gran arte moderno, que se distingue de todo arte que se aproximase al gusto popular o "de masa".

Una parte importante de la literatura de algunos "compañeros de viaje" de los grandes autores modernistas se dio en Río de Janeiro, ciudad preocupada en aquel momento por la expansión urbana y su función como capital del país. Se trata de una producción literaria que incorporaba el gusto, la fascinación por las nuevas conquistas del mundo moderno -la velocidad de los carros deportivos, la industrialización que llevaba el progreso hasta el universo doméstico- y el mundo del consumo a una postura estética que no menospreciaba lo que llamamos superfluo, el decorado que se iba incorporando a la cotidianidad de una ciudad que se quería, antes que nada, cosmopolita, como era el Río de Janeiro de los años veinte.

Cuando llamo a esta literatura de art-déco, la acerco, evidentemente, al gusto arquitectónico y a la influencia, primero francesa y luego americana, que tuvo. Es la literatura producida a partir de 1920 y, aunque se haya extendido hasta 1935, en 1930 comenzó a sufrir un fuerte proceso de exclusión.

En Río de Janeiro se da también otro factor: el cosmopolitismo, como gusto y comportamiento dominante, comienza a ser cuestionado e interpretado en tanto negación de la realidad del resto del país. Es emblemática la escena, fijada en foto y divulgada por la imprenta, de los combatientes gauchos que, victoriosos de la Revolución de 1930, amarraron sus caballos en el Obelisco. El monumento emblemático fue erguido como conmemoración y homenaje al final de las obras de apertura de la avenida Central, principal arteria de la ciudad, símbolo de la reforma urbana realizada por el alcalde Pereira Passos.

Tres autores, nacidos o radicados en Río de Janeiro, representan, de forma especial, esta literatura art-déco. Ellos son: Manuel Theotônio Freire Filho, el Théo Filho (1895-1973); una mujer, Cecília Moncorvo Bandeira de Melo (18701948), la Mme. Crysanthème; y, finalmente, el que más visibilidad logró alcanzar: Benjamin Costallat (1897-1961). ¿Qué tienen estos autores en común? Fueron todos ellos exitosos con el público. En un país de pocos lectores donde, hoy, las ediciones pocas veces pasan de tres mil volúmenes, estos autores llegaban -como es el caso de Costallat- a vender setenta mil ejemplares de una novela. Eran autores 
sintonizados con el gusto de "modernidad" del público, que publicaban novelas o practicaban en los periódicos y revistas la escritura de crónicas, género entonces entre el cuento y el reportaje, intrínsecamente ligado a la propia vida de la ciudad. No obstante, esta literatura no dejó trazo. Consideradas de "segunda clase" y a pesar de haber sido frecuentes en las estanterías de una gran parte de la población, sus obras no se encuentran en las grandes bibliotecas, como la Biblioteca Nacional en el centro de Río. Es decir, fueron absolutamente retiradas de las colecciones, de los acervos que deben abrigar obras únicamente consideradas "literatura". Rechazadas por el canon por poco modernas o excesivamente populares, no merecen estar en las instituciones culturales.

$\mathrm{Al}$ indagar sobre los orígenes del Movimiento Modernista, Mário de Andrade, en su conferencia de 1942, en la Casa del Estudiante en Río, hace el primer balance crítico de importancia sobre la Semana y discute las relaciones del movimiento entre Río de Janeiro y São Paulo:

¿Quién tuvo la idea de la Semana de Arte Moderno? No sé quién fue, nunca supe, solo puedo garantizar que no fui yo. [...] ya habíamos leído nuestros versos en Río de Janeiro; y en una lectura principal, en la casa de Ronald de Carvalho, donde también estaban Ribeiro Couto y Renato de Almeida, en una atmósfera de simpatía, Paulicéia desvairada obtenía el consentimiento de Manuel Bandeira, que en 1919 ensayara sus primeros versos libres en el Carnaval. [...] y el autor verdadero de la Semana de Arte Moderno fue Paulo Prado. Y solo una figura como él y una ciudad grande, mas provinciana como São Paulo, podrían hacer el movimiento modernista y objetivarlo en la Semana. (224)

Continuando con las diferencias de recepción posibles del movimiento modernista en las dos ciudades, Mário acierta de lleno en la peculiaridad del público de cada una de esas esferas públicas en 1922:

Ora, São Paulo estaba mucho más "a la par" que Río de Janeiro. Y, socialmente hablando, el modernismo solo podría ser importado por São Paulo y explotar en la provincia. Había una diferencia grande, ahora menos sensible, entre Río y São Paulo. Río era mucho más internacional, como norma de vida social. Está claro: puerto de mar y capital del país, Río posee un internacionalismo inherente. São Paulo era espiritualmente mucho más moderna, sin embargo, fruto necesario de la economía del café y del industrialismo consecuente. (226)

Las revistas ilustradas fueron, en la década de los años veinte, decisivas para la constitución del gusto en la ciudad y para la aceptación del artista por la crítica. 
Lo interesante y peculiar que me gustaría enfatizar aquí es un sistema que funcionaba en una especie de retroalimentación que se daba entre imprenta y arte, sobre todo entre las revistas ilustradas y la producción literaria, en el caso que estoy tratando. En estas revistas las narrativas estaban, muchas veces, acompañadas de ilustraciones, como las del caricaturista J. Carlos, quien consagró sus dibujos a los personajes urbanos de inicios del siglo: mujeres seductoras y con grandes escotes, las "melindrosas" y figuras masculinas poco ortodoxas, variaciones del dandy con sus imágenes andróginas.

Es de estos personajes y de la ciudad del Río de Janeiro, de los espacios por donde circulan, que habla la literatura de los autores que trato. Si sus nombres y sus obras suenan desconocidos, no es sin razón. Estos autores de absoluto éxito entre el público, provocadores ellos mismos de opinión en la esfera pública, se convirtieron en ejemplos de la eficacia del canon.

Mme. Crysanthème y Théo Filho actuaron como periodistas de importancia en la época. Théo Filho creó y dirigió la primera revista dedicada exclusivamente a la crítica literaria y a la divulgación de publicaciones, $O$ Mundo Literário, de la que Crysanthème fue colaboradora regular. Novelista de gran popularidad, los títulos de las novelas de Théo Filho ya dicen mucho: 365 días de boulevard, Playa de Ipanema, Romance tropical y La gran felicidad. Folletinista famoso, terminó siendo más conocido como periodista: fue víctima de su propio éxito y anticipó los problemas que la seducción del best seller acarreará a autores posteriores a él.

Es de Théo Filho la novela que me parece la más importante de esta época: Ídolos de barro, crítica y política. En ella es preciosa la descripción que hace de la ciudad, sus bares y restaurantes, nítidamente divididos según sus visitantes, pero todos muy cercanos, pues parece haber una intimidad sorprendente entre los habitantes de la ciudad de las áreas pobres y los de las más ricas. Su novela Playa de Ipanema, premonitorio de su fabulación sobre la especulación inmobiliaria, fue republicada por la editora Dantes.

El más popular fue Benjamin Costallat. Costallat era, sobre todo, un cronista de la ciudad. Los propios títulos de sus obras apuntan hacia sus características: gusto cosmopolita, interés por la influencia americana que surgía a través de la arquitectura de los skyscrapers y del cine, y atención a la conquista del público consumidor de libros. Cabe destacar, por la propia expresividad de los títulos: Misterios de Río, Modernos, Mutt, Jeff \& Cía, Fitas y Arranha Céu. Más allá de la literatura, dos características determinan su peculiaridad: primero, el trato del libro como objeto que debe despertar el interés del lector por su aspecto visual; como dijo él en la introducción a Mutt, feff \& Cía, "brillantes portadas de artistas 
brillantes". Dentro de estos artistas están los ilustradores Álvarus y J. Carlos y el pintor modernista Di Cavalcanti.

Además de esto, la idea que Costallat defendía de la profesionalización del escritor, que debía ganar la vida y sustentar a su familia con su pena, incluía su disposición para escribir textos de reclames, anuncios para periódicos, revistas y tranvías. Lo curioso de estos anuncios es que en ellos Costallat transponía no solo su estilo sino también alguna cosa de sus personajes. La popularidad que Benjamin Costallat alcanzó con la novela Melle. Cinema hizo que se volviera, principalmente, redactor de productos que, de alguna forma, se relacionaran con la idea de cosmopolitismo, "vida moderna" y... seducción.

Dentro de sus obras, Melle. Cinema, "novela de costumbres", publicada en 1923, fue el mayor suceso editorial de la Primera República: 75.0oo ejemplares en cinco años, y alcanzó, según el último registro que se obtuvo, 140.000 ejemplares.

París, cigarros, amores, cocaína y una discreta prostitución atraviesan casi toda la novela. Nada que no hiciese parte de la mejor tradición del folletín francés en la historia de Melle. Cinema, la garçonne americana, la pequeña liviana del siglo del shimmy, la criaturita educada en el sonido del jazz.

El enorme éxito de Melle. Cinema llevará el autor a crear $O$ marido de $\mathrm{Me}$ lle. Cinema. Se repetía el gesto creador de J. Carlos. Al lado de la melindrosa se ponía al dandy, fútil pero excelente bailaor; ignorante, pero al tanto de todas las novedades; pobretón, mas siempre a la última moda de los "grandes magazines". Rosalina va a terminar sus aventuras al volante de su deportivo rojo, al morir en la avenida Niemeyer. Es la novela que trae, por primera vez, el "estilo Copacabana" a la literatura.

Cito un fragmento del primer capítulo del libro:

En los cantos de la sala y del balcón oscuro algunas parejas "coqueteaban".

Rosalina, en la ventana, observaba.

Por la avenida Atlántica se cruzaban los carros veloces.

La playa, con su collar iluminado, se extendía muy blanca en la noche oscura. Una linda luz de luna plateaba el océano. (21)

Costallat publicó novelas hasta alrededor de 1936 y continuó siendo cronista del fornal do Brasil hasta su muerte, en 1961.

Alrededor de 1931, hubo un auge del déco y apareció la experiencia plural de la importante revista Bazar, injustamente poco estudiada. A comienzos de la década de 1930, el estilo art-déco se tornó popular en la ciudad. El crecimiento de Copacabana era un hecho y surgían los barrios modernos de arquitectura y decoración art-déco. La arquitectura de los cines copiaba modelos americanos en 
las fachadas y en los interiores. Las revistas dedicadas al cine se hacían populares pues se ocupaban de las vamps, modelo de moda y comportamiento.

La mayor prueba de la popularidad del art-déco está en la construcción de lo que sería el principal símbolo de la ciudad, la estatua del Cristo Redentor, en el monte del Corcovado, en Laranjeiras. Obra del escultor francés Paul Landowski sobre trazo del italiano Lélio Landucci y del ingeniero brasileño Heitor da Silva Costa, la estatua fue hecha con materiales considerados modernos y especialmente en corte déco.

La construcción de la estatua fue repudiada fuertemente por algunos de los modernistas cariocas sofisticados, como Ronald de Carvalho, escritor y diplomático. Debo confesar que yo misma, tal vez por haber crecido en una familia fuertemente anticlerical, siempre consideré un tanto de mal gusto aquella imagen con frecuencia reproducida en pequeñas estatuillas, empeoradas muchas veces por las terribles iluminaciones fluorescentes.

En 2002, en una especie de estrategia de marketing, la Alcaldía de Río de Janeiro promovió una encuesta popular sobre cuál sería el más importante (y querido) símbolo de la ciudad. Entre los finalistas quedaron nuestro magnífico conjunto de playas y el Pão-de-Açúcar, pero el gran victorioso fue el mismo Cristo Redentor, en el Corcovado. En 2007 fue considerado una de las siete nuevas maravillas del mundo. ¡Venganza del art-déco!

Volvamos a Bazar. Es realmente curioso que esta revista quincenal, publicada en Río de Janeiro durante el año 1931 (al menos los números existentes en diversos archivos cariocas solo guardan volúmenes de este año), sea tan solemnemente ignorada por la crítica, por los estudiosos del modernismo y del periodismo, de las artes gráficas y del diseño. Bazar es una revista extremamente innovadora desde el punto de vista gráfico, sofisticada y sintonizada con los tiempos modernos del buen gusto y del consumo, como ella misma se define en sus anuncios.

El patrón estético de la revista, evidenciado por el logotipo, es el del artdéco. De gusto art-déco también son las esculturas reproducidas en varias fotos, los muebles de decoración anunciados y los apartamentos visitados. Se trata de la decoración en su nuevo sentido, aplicado en el espacio interior y la vida cotidiana.

Es importante anotar que el comité de redacción de la revista reúne, lado a lado, a simbolistas como Felippe d'Oliveira (cabe observar que una de las más bellas obras art-déco de Río de Janeiro es su túmulo en el cementerio São João Batista); Olegário Mariano (cuasi parnasiano); la pintora expresionista Bella la Paes Leme; uno de los participantes del grito modernista en São Paulo, Guilherme de Almeida, y al arquitecto modernista más importante de aquel momento, 
Lúcio Costa, quien ya hace algún tiempo estaba dedicado a la renovación estética a través de combates como los que promueve con la Escuela de Bellas Artes y al frente de la organización del Salón Nacional de Bellas Artes.

Lo que las portadas de la revista evidencian es una propuesta no sectaria, ecléctica, con imágenes de los principales ilustradores de aquel momento. En publicación de tal gusto y sofisticación no podría faltar una portada realizada por el ilustrador art-déco más importante del momento, el francés Paul Colin, conocidísimo por sus afiches, especialmente aquellos en que tornó la célebre imagen de la cantante Joséphine Baker.

El periodismo refinado de algunos redactores que hicieron escuela registra el gusto de un artista-personaje como el escultor art-déco Humberto Cozzo, cuya obra El beso es reproducida en la revista y presentada, exactamente, en el mismo estilo de la literatura de nuestros expurgados "compañeros de viaje":

Manejando la limosina por el esplendor ondeante de Copacabana, entre la cauda verde del océano-pavo y las espaldas morenas de la playa-mujer, Humberto Cozzo nos cuenta su vida emocionante de artista. Ascendente, en un gusto nítido de índice. Plástica y luminosa como bloque de mármol vivo.

(Bazar, año I, n. ${ }^{\circ}$ 3, 56)

Los mismos redactores caracterizan a Bella como una "pintora vigorosa de espíritu modernísimo".

Es en Bazar que Carlos Drummond de Andrade publica poemas que aparecerán en sus primeros libros: "Rio de Janeiro", que hace parte de Linterna mágica, una serie de poemas sobre ciudades de su primer libro; "Alguna poesía", también de 1931, y "Sombra de las muchachas en flor" que solo sería publicado en libro en 1934, en Brejo das almas.

Por otra parte, Bazar tiene a Guilherme de Almeida como "corresponsal" en São Paulo, desde donde envía reportajes, como el curioso texto "Cosmópolis" y también publican "primíparos" que adquirieron renombre en el universo poético modernista. El 21 de octubre de 1931, la revista publica "Paysage", poema en francés de un autor que aún se hace llamar Murilo Monteiro Mendes. En el número de noviembre ya es Murilo Mendes quien publica "Rua do ouvidor" ("Dejo el alma en el perchero..."), poema que acompaña un reportaje y una foto del pintor Cícero Dias en las arenas de la playa de Copacabana. Así mismo participan en la revista Jorge de Lima y Ribeiro Couto. La contribución de Mário de Andrade viene a través del poema "Crepúsculo urbano".

Tal vez la indicación más significativa de la necesidad de una relectura que permita una apertura efectiva para la superación de fronteras definitorias y 
limitadoras es la importancia dada, a través del reportaje fotográfico, a la película Límite de Mário Peixoto. Retirar el art-déco de espacios de exclusión generados por nuestra crítica tal vez haría posible comprender mejor a otro Mário Peixoto, el novelista y el poeta.

Para finalizar, caben algunas referencias con respecto a la construcción de una de las más importantes imágenes del modernismo en Río de Janeiro y su relación con el final del movimiento art-déco. El esclarecido ministro Gustavo Capanema, responsable de la cartera de Educación y Salud Pública, fue, en gran parte, el responsable de la victoria del modernismo en Río de Janeiro y la palanca de una de las más importantes expresiones del modernismo Brasileño, la arquitectura. En 1935, Capanema abre un concurso destinado a recibir proyectos arquitectónicos para la construcción del edificio sede del ministerio. El ganador es un proyecto art-déco, en su versión marajoara, de Archimedes Memória. Capanema, contrariado con el resultado que incluso desclasificaría dos trabajos modernistas, el de Affonso Reidy y el de Jorge Moreira y Ernani Vasconcelos, entrega el premio, mas descubre que nada en la convocatoria lo obligaba a construir el edifico siguiendo aquel modelo.

El proyecto y el concurso eran muy infelices, y todo indica que sus jueces no eran los más idóneos, ya que el jurado era cercano al catedrático de "grandes composiciones". Es una pena que con este hayan sido excluidos también todos los otros proyectos de tendencia art-déco, estilo que, a partir de ahí, sería considerado de absoluto mal gusto.

Entregado el premio y sin proyecto a realizarse, Capanema convoca a sus asesores modernistas -Manuel Bandeira, Carlos Drummond de Andrade y Rodrigo Melo Franco de Andrade- y acaba por entregar a Lúcio Costa la responsabilidad de la construcción. Lúcio Costa lleva a Río al arquitecto modernista francés Le Corbusier, de cuyo trazo original deriva, finalmente, el proyecto. El edificio reúne en su construcción a la pareja que en los años sesenta elevará el monumento urbano modernista más radical, Brasilia, la nueva capital: Lúcio Costa y Oscar Niemeyer. A Cândido Portinari se le encargó pintar frescos y murales del edificio en construcción.

El Capanema, como pasó a ser conocido, fue inaugurado en 1945, no sin que antes la cuestión de la identidad nacional saliera a la superficie más de una vez y, con esta, los peligros del pensamiento único, del dogmatismo, del exclusivismo del canon y, especialmente, de los nacionalismos. En el palacio, los frescos y paneles de Portinari, dentro de la perspectiva muralista tan cara en aquel momento al arte latinoamericano, con José Vasconcelos (ministro de la Educación en México) y Diego Rivera, convivieron con el paisajismo inédito de Burle Marx. 
Sin embargo, cuando se trató de las esculturas deseadas por el ministro, las cosas, curiosamente, se complicaron. Se encargaron diversos trabajos, todos excelentes ejemplos del arte brasileño en tres dimensiones. Para el frente del edificio, no obstante, Capanema deseaba algo grandioso y, como nadie pasa impune por los regímenes autoritarios, como el primer gobierno de Getúlio Vargas, el ministro ambicionó colocar en la entrada del edificio una inmensa escultura de carácter nacionalista: el Hombre brasileño.

Pero ¿qué es al final el "hombre brasileño"? ¿Qué cara, altura y porte tendría? Drummond interfiere, como había hecho antes para tranquilizar los ánimos de Lúcio Costa cuando este amenazó con dejar el proyecto. Después de consultas a antropólogos y otros estudiosos destinados a definir teóricamente cómo sería ese "hombre brasileño", Capanema encarga la gran estatua a Celso Antônio, responsable de otros trabajos en el palacio. Capanema quiere un hombre de perfil ario. Celso Antônio cree que debe crear a un mestizo sentado. Roquette Pinto escribe al ministro para decir que el hombre brasileño jamás podría ser representado sentado, pero sí en movimiento. Drummond, entonces, escribe a Celso Antônio y suspende el trabajo. Se intenta con otro artista invitado, Ernesto de Fiori. Tampoco funciona. Drummond pide que Mário de Andrade consiga que el escultor Brecheret se decida a crear a aquel hombre. Mário se reconoce incapaz de insistir en el encargo y el artista, de crear la obra.

Y así terminamos. El edificio fue inaugurado en 1945 sin la estatua del Hombre brasileño, imposible de ser representado. En la parte frontal del edificio, el conjunto Monumento de la juventud, de Bruno Giorgio, continúa dando cuenta del recado.

\section{Obras citadas}

Bazar. Revista Ilustrada. Río de Janeiro: Editorial Bazar, 1931.

Costallat, Benjamin. O marido de Melle. Cinema. 2. ${ }^{\mathrm{a}} \mathrm{ed}$.

Río de Janeiro: Livraria Antunes, 1931.

Portoghesi, Paolo. Album degli anni venti. Roma: Laterza, 1976.

Williams, Raymond. "Metropolitan Perceptions and the Emergence of

Modernism". The Politics of Modernism. Londres: Verso, 1996. 37-48. 